\title{
VIOLAÇÕES DE DIREITOS DA PERSONALIDADE E INDENIZAÇÃO POR EDIÇÕES DE PÁGINAS DA WIKIPÉDIA ${ }^{1}$
}

\author{
Marcelo Guerra Martins*
}

SUMÁRIO: Introdução; 2 Características Fundamentais da Wikipédia; 3 Violação de Direitos da Personalidade no Âmbito da Wikipédia; 4 Responsabilização da Empresa por Atos de Pessoa a seu Serviço Junto à Wikipédia; 5 Parâmetros para a Indenização pelos Danos Morais; 6 Conclusões; Referências.

RESUMO: O presente artigo apresenta as características essenciais da Wikipédia, um fenômeno típico da Sociedade da Informação. Tendo em vista que o conteúdo dessa enciclopédia pode ser editado por qualquer usuário, bem como em face da Wikipédia ter ganhado alguma credibilidade social, o texto examina o problema das edições que geram danos a direitos de personalidade como intimidade, imagem e honra de pessoas e a respectiva indenização. Dentro do tema, o texto também aborda a questão da responsabilidade da empresa por inserções realizadas por empregados, mesmo que fora de suas atribuições e, ainda, os parâmetros para a fixação do valor referente aos danos morais. Em termos de metodologia, o presente texto se constitui em um estudo bibliográfico (doutrina) e de jurisprudência, cujo caráter é primordialmente qualitativo e indutivo. As conclusões apresentam os possíveis parâmetros a serem aplicados pelos juízes a título de indenização.

PALAVRAS-CHAVE: Danos morais; Direitos de personalidade; Responsabilidade; Wikipédia.

\section{VIOLATIONS OF THE PERSON'S RIGHTS AND INDEMNITY DUE TO WIKIPEDIA EDITIONS}

ABSTRACT: The basic features of Wikipedia, a phenomenon typical of the Information Society, are forwarded. Since the contents of the encyclopedia may be edited by anyone and since it has obtained a sufficient social credibility, current paper examines editions that damage the person's rights, such as intimacy, image and honor of people and their respective indemnity. The issue of the firm's responsibility in insertions by employees, even beyond their attributions, and the parameters for the fixation of rates for moral damage, are debated. The paper

\footnotetext{
${ }^{1}$ Este artigo é fruto de projeto desenvolvido no âmbito do Mestrado em Direito da Sociedade da Informação das Faculdades Metropolitanas Unidas (FMU), na linha de pesquisa: negócio jurídico na Sociedade da Informação.

* Docente no Programa de Mestrado em Direito da Sociedade da Informação das Faculdades Metropolitanas Unidas (FMU), São Paulo (SP), Brasil; Doutor em Direito do Estado pela Universidade de São Paulo (USP/SP); Juiz Federal em São Paulo, Brasil.E-mail: marcelo.martins@fmu.br
} 
comprises a bibliographical (doctrine) and juridical analysis, with qualitative and inductive characteristics. Possible parameters that may be applied by judges in indemnity cases are provided.

KEY WORDS: Wikipedia; Person's rights; Responsibility; Moral damage.

\section{VIOLACIÓNES DE DERECHOS DE LA PERSONALIDAD Y COMPENSACIÓN POR LAS EDICIONES EN LAS PÁGINAS DE LA WIKIPÉDIA}

RESUMEN: Este artículo presenta las características esenciales de la Wikipedia, un fenómeno típico de la sociedad de la información. Teniendo en cuenta que el contenido de la enciclopedia puede ser editado por cualquier usuario, y debido la Wikipedia han ganado algo de credibilidad social, se examina el problema de los problemas que generan daños a los derechos de la personalidade de privacidad, a la imagen y el honor de las personas y su compensación. Dentro del tema, el texto también aborda la cuestión de la responsabilidad corporativa para las inserciones realizadas por los empleados, incluso fuera de sus funciones, así como los parámetros para determinar el monto de los daños morales. En cuanto a la metodología, este texto constituye un estudio bibliográfico (doctrina) y la jurisprudencia, cuyo carácter es principalmente cualitativo e inductivo. Los hallazgos muestran los posibles parámetros que se aplicarán por los jueces como compensación.

PALABRAS-CLAVE: Daño moral; Derechos de la Personalidad; Responsabilidad; Wikipedia.

\section{INTRODUÇÃO}

A humanidade vive a chamada era da Sociedade da Informação, período em que a difusão de ideias e informações, bem como a criação, o processamento e a armazenagem de conhecimento passam a ter, cada vez mais, papel de protagonismo nos arranjos socioeconômicos dos diversos povos, a tal ponto de o valor do conjunto dos bens imateriais suplantar o equivalente dos bens materiais.

No final do século passado, Alvin Toffler já aventava que "a informação tornou-se talvez o negócio mais importante e o que mais cresce no mundo"3.

3 TOFFLER, Alvin. A terceira onda. 18. ed. São Paulo: Record, 1980, p. 162. Ainda segundo o autor, a humanidade começa a viver a denominada Terceira Onda, cuja civilização "terá à sua disposição mais informação - e informação mais minuciosamente organizada a respeito de si mesma do que se podia imaginar ainda há apenas um quarto de século" (id., p. 182). 
Tanto isso é efetivo que, segundo Paula Forgioní, "a propriedade intelectual é o maior produto de exportação dos Estados Unidos". Com efeito, a informação e o conhecimento são os atores centrais da produção econômica da nossa era.

Nota-se, de fato, que cada época possui sua matriz principal de geração de riquezas. Nessa toada, Siqueira Júnior explica que

na era agrícola, a terra se configurava como o fator primordial da geração de riquezas. Na era industrial a riqueza surge da máquina a vapor e da eletricidade. Na era do conhecimento, a informação e o conhecimento são os atores centrais da produção econômica 5 .

O surgimento da Internet certamente representou um novo paradigma na maneira de os seres humanos se comunicarem. Foi a partir da disseminação mundial da grande rede que bilhões de pessoas passaram a contatar outros tantos bilhões ${ }^{6}$ de modo instantâneo e a custos cada vez mais baixos, inclusive sem que autoridades censoras possam controlar efetivamente o conteúdo das mensagens que se disseminam em velocidade espantosa.

Se, de um lado, toda essa ampla e efervescente liberdade é extremamente positiva, constituindo-se em elemento de enorme irritação para governos autoritários ou que pouco se interessem pelo bem-estar da população (v.g. basta lembrar as convulsões da recém Primavera Árabe), de outro representa um desafio à preservação de direitos da personalidade como intimidade, imagem e honra, dadas as frequentes notícias da prática de ofensas ou do chamado cyberbullyng ${ }^{7}$, cujas consequências danosas, tanto em termos materiais quanto morais, costumam ser marcantes e, muitas vezes, permanentes.

Infelizmente, segundo narra Eduardo C. B. Bittar, "pessoas vêm cometendo suicídio, tamanha a desonra, a ofensa, a lesividade e a massividade da exposição da intimidade, a partir de atos de terceiros (conhecidos ou não) praticados pelos meios virtuais"s.

4 FORGIONI, Paula A. Os fundamentos do antitruste. 8. ed. São Paulo: Revista dos Tribunais, p. 313.

5 SIQUEIRA JÚNIOR, Paulo Hamilton. Habeas data: remédio jurídico da sociedade da informação. In: PAESANI, Liliana Minardi (Coord.). O direito na sociedade da informação. São Paulo: Atlas, 2007, p. 255.

6 Na visão de Manuel Castells, a Internet se mostra como "um meio de comunicação que permite, pela primeira vez, a comunicação de muitos com muitos, num momento escolhido, em escala global". CASTELLS, Manuel. A galáxia da internet. Trad. Maria Luiza X. de A. Borges. Rio de Janeiro: Zahar, 2003, p. 08.

7 Explica Lucas de Oliveira Rodrigues que é "justamente esse ato de maltratar ou violentar o outro de forma sistemática e repetitiva que é denominado bullying. Falamos de cyberbullying, então, quando a agressão se passa pelos meios de comunicação virtual, como nas redes sociais, telefones e nas demais mídias virtuais". RODRIGUES, Lucas de Oliveira. Cyberbullying. Brasil Escola. Disponível em: < http://brasilescola.uol.com. br/ sociologia/cyberbullying.htm >. Acesso em: 06 fev. 2016.

8 BITTAR, Eduardo C. B. Internet, cyberbullyng e lesão a direitos da personalidade: o alcance atual da teoria da reparação por danos morais. Homenagem a José de Oliveira Ascensão. In: SIMÃO, José Fernando; BELTRÃO, Silvio Romero (Coord.). Direito civil: estudos em homenagem a José de Oliveira Ascensão. São Paulo: Altas, vol. 1, 2015, p. 279-280. 
As chamadas redes sociais, tais como o Facebook e outras do gênero, são terrenos bastante férteis para a proliferação de ofensas dos mais variados gêneros, seja pela publicação de imagens íntimas e não autorizadas das pessoas, seja através da divulgação de inverdades, ou mesmo por meio dos comentários de cunho pejorativo que, afastando-se da mera crítica, têm por objetivo principal causar mal-estar nos respectivos destinatários.

Um tema pouco abordado até o momento são os danos (materiais e morais) decorrentes de edições em páginas da Wikipédia que tragam informações inverídicas, apresentem cunho pejorativo ou, ainda, distorçam uma realidade, principalmente se o objeto das edições forem pessoas notórias ou em posições sociais de proeminência, tais como artistas, jornalistas, empresários, autoridades públicas, etc.

Como sabido, o sistema da Wikipédia é colaborativo, isto é, comporta inserções de qualquer usuário que, em tese, deve observar certas regras limitadoras e de comportamento a fim de preservar os objetivos essenciais da enciclopédia. Todavia, nem sempre esses limites são respeitados por pessoas que, movidas por dolo ou mera culpa, acrescentam trechos indevidos que terminam por causar danos a terceiros que, evidentemente, buscam a respectiva indenização.

Dentro dessa temática há ainda duas questões. A primeira é acerca da possibilidade de responsabilizar-se a empresa pelos danos causados por pessoa a seu serviço (seja empregado, preposto, agente, autônomo, etc.) que promove inserções em páginas da Wikipédia, mesmo que esse ato nada tenha a ver com as funções laborais ordinariamente desenvolvidas pelo causador do dano.

A segunda questão gira em torno da quantia a ser arbitrada pelo juiz a título dos danos morais em cada hipótese concreta, eis que, ao contrário do que ocorre em relação aos danos materiais, o valor dos danos morais não se harmoniza com os parâmetros tradicionais contábeis de aferição.

É o que nos propomos a abordar, ficando advertido, desde logo, que não pretendemos esgotar todas as nuances envolvidas no tema em foco que, por ainda ser pouco explorado, torna-se rico e instigante per se. Logo, críticas e contribuições são sempre bem-vindas.

\section{CARACTERÍSTICAS FUNDAMENTAIS DA WIKIPÉDIA}

Conforme informado em seu site na Internet, a Wikipédia é um projeto de enciclopédia eletrônica coletiva universal e multilíngue que tem como objetivo 
fornecer um conteúdo reutilizável livre, objetivo, verificável e atualizável por qualquer usuário". O seu conteúdo é disponibilizado sob a licença da Creative Commons BY-SA e pode ser copiado e reutilizado sob a mesma licença inclusive para fins comerciais.

Evidentemente, sob pena de se transmudar em uma colcha de retalhos imprestável a qualquer tipo de pesquisa, a inserção de novos conteúdos e atualizações na Wikipédia necessita observar algumas diretrizes elementares dispostas em seu site, denominados de pilares, a seguir resumidos.

O primeiro pilar estatui que a "Wikipédia é uma enciclopédia de amplo escopo que compreende elementos de enciclopédias generalistas, de enciclopédias especializadas e de almanaques"10. Portanto, a enciclopédia "não é um repositório de informação indiscriminada [...] não é um dicionário, não é uma página onde se coloca o currículo, um fórum de discussão, um diretório de ligações ou uma experiência política"11.

Dessa maneira, a "Wikipédia não é local apropriado para inserir opiniões, teorias ou experiências pessoais. Todos os editores da Wikipédia devem seguir as políticas que não permitem a pesquisa inédita e procurar ser o mais rigorosos possível nas informações que inserem"12.

Com efeito, não é permitido publicar pesquisas inéditas, ou seja, "os artigos não devem conter conceitos, recolha de dados, pesquisas ou teorias que não tenham sido anteriormente publicados em veículos adequados e reconhecidos para o efeito"13. Esta política pode ser identificada pelas siglas NPI ou NOR, abreviação de No Original Research.

Mas não é só isso, uma vez que os artigos igualmente "não devem conter análises ou interpretações inéditas de temas, conceitos, dados, ideias já publicadas [...], pois a finalidade da enciclopédia não é defender uma posição ou visão sobre determinado tema" ${ }^{14}$, o que se liga com o objeto do segundo pilar visto a seguir.

O segundo pilar determina que a Wikipédia é regida pela imparcialidade "o que implica que nenhum artigo deve defender um determinado ponto de vista" ${ }^{\text {, }}$,

\footnotetext{
Todas as informações e transcrições a seguir foram colhidas no site da Wikipédia. Disponível em: <https:// pt.wikipedia.org > . Acesso em: 10 mar. 2016.

${ }^{10}$ Disponível em: < https://pt.wikipedia.org/wiki/Wikip\%C3\%A9dia:Cinco_pilares > Acesso em: 10 mar. 2016.

${ }^{11}$ Disponível em: < https://pt.wikipedia.org/wiki/Wikip\%C3\%A9dia:Cinco_pilares>. Acesso em: 10 mar. 2016.

12 Disponível em: < https://pt.wikipedia.org/wiki/Wikip\%C3\%A9dia:Cinco_pilares>. Acesso em: 10 mar. 2016.

${ }^{13}$ Disponível em: < https://pt.wikipedia.org/wiki/Wikip\%C3\%A9dia:Nada_de_pesquisa_in\%C3\%A9dita > Acesso em: 10 mar. 2016.

14 Disponível em: <https://pt.wikipedia.org/wiki/Wikip\%C3\%A9dia:Refer\%C3\%AAncias_e_boa-f\%C3\%A9>. Acesso em: 10 mar. 2016.

15 Disponível em: < https://pt.wikipedia.org/wiki/Wikip\%C3\%A9dia:Cinco_pilares>. Acesso em: 10 mar. 2016.
} 
sendo ainda importante "justificar verbetes com fontes reputadas sempre que necessário, sobretudo em casos relacionados com temas controversos"16.

É que a citação "mostra ao leitor a verificabilidade do artigo e o auxilia a encontrar mais informação. Se você consultar uma fonte externa ao escrever um artigo, citá-la é honestidade intelectual básica"17. Em síntese, "os artigos na Wikipédia devem conter apenas material que possa verificar-se ter sido publicado em fontes fidedignas" ${ }^{18}$.

Em complemento, nenhum "ponto de vista deve ser apresentado como o 'verdadeiro' e/ou o 'melhor', tampouco como o 'falso' e/ou o 'pior"' ${ }^{19}$. Nesse contexto, há recomendação expressa no site para tomar "cuidado com a tentação de escrever frases maliciosas, como 'Alguns dizem..."”20.

O terceiro pilar estabelece que a enciclopédia é livre, quer dizer, encontrase ela edificada de maneira que qualquer pessoa possa "criar, copiar, modificar e distribuir o conteúdo da Wikipédia"21. De fato, "nenhum artigo possui dono e ninguém tem o controle de um artigo em particular"22, cujo conteúdo "pode ser modificado e redistribuído sem aviso prévio por qualquer pessoa, inclusive de forma comercial" ${ }^{23}$.

No contexto do terceiro pilar é ainda previsto que as "contribuições também não devem violar nenhum direito autoral (copyright), nem serem incompatíveis com o licenciamento da Wikipédia"24.

O quarto pilar aduz que as modificações na Wikipédia devem observar certas normas de conduta, iniciando pela recomendação de que o usuário se comporte "de forma civilizada, evite fazer ataques pessoais e generalizações. Mantenhase calmo durante as disputas, procure o consenso e evite guerras de edições [...] Sobretudo, assuma a boa-fé" 25 .

Devem ser evitados, nessa linha, ataques pessoais, adjetivações negativas,

${ }^{16}$ Disponível em: < https://pt.wikipedia.org/wiki/Wikip\%C3\%A9dia:Cinco_pilares>. Acesso em: 10 mar. 2016.

17 Disponível em: < https://pt.m.wikipedia.org/wiki/Wikip\%C3\%A9dia:Livro_de_estilo/Cite_as_fontes\#Refer. C3. AAncias_vs._bibliografia >. Acesso em: 10 mar. 2016.

18 Disponível em: $<$ https://pt.wikipedia.org/wiki/Wikip\%C3\%A9dia:Verificabilidade>. Acesso em: 10 mar. 2016.

19 Disponível em: < https://pt.wikipedia.org/wiki/Wikip\%C3\%A9dia:Cinco_pilares > . Acesso em: 10 mar. 2016.

20 Disponível em: < https://pt.m.wikipedia.org/wiki/Wikip\%C3\%A9dia:Livro_de_estilo/Cite_as_fontes\#Refer. C3. AAncias _vs._bibliografia >. Acesso em: 10 mar. 2016.

${ }^{21}$ Disponível em: $<$ https://pt.wikipedia.org/wiki/Wikip\%C3\%A9dia:Cinco_pilares > . Acesso em: 10 mar. 2016.

${ }^{22}$ Disponível em: < https://pt.wikipedia.org/wiki/Wikip\%C3\%A9dia:Cinco_pilares > . Acesso em: 10 mar. 2016.

${ }^{23}$ Disponível em: <https://pt.wikipedia.org/wiki/Wikip\%C3\%A9dia:Cinco pilares > . Acesso em: 10 mar. 2016.

${ }^{24}$ Disponível em: < https://pt.wikipedia.org/wiki/Wikip\%C3\%A9dia:Cinco_pilares> $>$. Acesso em: 10 mar. 2016.

25 Disponível em: < https://pt.wikipedia.org/wiki/Wikip\%C3\%A9dia:Cinco_pilares>. Acesso em: 10 mar. 2016. 
insinuações maliciosas, desqualificações, comentários racistas ou preconceituosos, ofensas, sem falar, obviamente, em qualquer tipo de ameaça. Conforme adverte o site, em "nenhum tipo de discussão há a necessidade de apelar para esse recurso e muito menos com palavras insultuosas como: 'infeliz', 'burro', 'estúpido', 'criançola' etc.".

Por fim, desde que respeitados os pilares acima, a criação e edição dos artigos é fortemente incentivada na Wikipédia. Nessa banda, há trechos em que é enfatizado "não ser necessário alcançar a perfeição na primeira vez".

Ainda com objetivo de estimular as colaborações dos usuários, há recomendações do tipo "não se iniba de editar por temer colocar as coisas de pernas para o ar", na medida em que "as versões dos artigos são preservadas num histórico, de modo que não é possível danificar definitivamente a Wikipédia ou destruir irremediavelmente a informação".

Os usuários da Wikipédia compõem a chamada comunidade que "pode deliberar sobre várias coisas: algum artigo em especial, os atributos dos usuários, a eliminação de páginas, etc.". Essas decisões "são a instância maior dentro da Wikipédia em português" e são tomadas por consenso.

Porém, na Wikipédia, o consenso não equivale necessariamente à unanimidade nem significa o mero resultado de contagem de votos. Em suma, "a tomada de decisões pressupõe em esforço para integrar as preocupações legítimas de todos os editores, ao mesmo tempo que deve respeitar as políticas e recomendações anteriormente acordadas pela comunidade"26.

Para casos mais graves, existe a possibilidade do bloqueio de determinado usuário, "de forma que fique impedido de editar em todos os domínios da Wikipédia ou apenas em alguma porção dela" ${ }^{27}$. Todavia, essa medida extrema somente pode ser tomada pelos chamados administradores e revisores ${ }^{28}$.

Todo esse modus operandi peculiar tornou a Wikipédia um instrumento de

\footnotetext{
${ }^{26}$ No site da Wikipédia há explicações detalhadas acerca do atingimento do consenso. Disponível em: <https:// pt.wikipedia.org/wiki/Wikip\%C3\%A9dia:Consenso\#N.C3.ADvel de consenso > . Acesso em: 09 fev. 2016.

27 Disponível em: <https://pt.wikipedia.org/wiki/Wikip\%C3\%A9dia:Pol\%C3\%ADtica_de_bloqueio >. Acesso em: 10 mar. 2016.

${ }^{28}$ Administradores são usuários com direitos de operador de sistema (sysop). Essa atribuição pode ser dada a qualquer usuário que tenha sido um colaborador por certo tempo, encarado como um membro da comunidade conhecido e digno de confiança, e que possui ao menos 2.000 edições no domínio principal e uma conta com ao menos seis meses de registro. Atualmente, além destes requisitos, o candidato precisa passar por um sufrágio, de acordo com a política de administradores. A função de reversão (rollback) é uma ferramenta disponível aos administradores e aos reversores (rollbacker), que possibilita reverter edições rapidamente, sejam elas edições próprias ou de outros usuários. No âmbito da Wikipédia, há apenas 129 reversores, que, juntamente com os administradores, constituem um total de 197 usuários com esse tipo de permissão especial. Disponível em: < https://pt.wikipedia.org/wiki/Wikip\%C3\%A9dia:Administradores > Acesso em: 10 mar. 2016.
} 
pesquisa bastante conhecido e utilizado por milhões de pessoas ao redor do mundo. É indiscutível que a enciclopédia ganhou credibilidade entre o grande público que a vê como uma fonte confiável de informações e conhecimento.

Aliás, o próprio Poder Judiciário já se serviu do conteúdo da Wikipédia para fundamentar decisão. Nesse sentido, a Primeira Turma Recursal Cível do Rio Grande do Sul, em 16 de abril de 2013, na apelação $n^{0} 71004356218$, baseou-se em informação constante da enciclopédia para confirmar decisão judicial monocrática que havia determinado a internação de paciente em hospital ante a negativa do Plano de Saúde.

Segundo restou consignado no acórdão, ainda "que não se trate de uma fonte técnica, também não se pode desprezar pura e simplesmente a informação de lá extraída, ainda mais porque a embargante não trouxe qualquer elemento probatório em sentido contrário".

Não se está aqui afirmando, é bom esclarecer, que as informações constantes da Wikipédia são sempre confiáveis e, portanto, se prestam a embasar pesquisas científicas ou de elevada acuidade técnica. Chama-se a atenção apenas para o fenômeno da permeabilidade social da enciclopédia como ferramenta de pesquisas gerais e cujo conteúdo é respeitado pelo grande público.

Nessa linha de raciocínio, é de se concordar que uma inverdade ou ofensa depreciativa lançada na Wikipédia pode ser bem mais gravosa do que quando alocada em outras redes sociais, tais como Facebook, Youtube, Qzone, Whatsapp, Twitter, etc., que não contam com a mesma credibilidade.

\section{VIOLAÇÃO DE DIREITOS DA PERSONALIDADE NO ÂMBITO DA WIKIPÉDIA}

Direitos da personalidade, segundo Silvio Romero Beltrão, são uma "categoria especial de direitos subjetivos que, fundados na dignidade da pessoa humana, garantem o gozo e o respeito ao seu próprio ser, em todas as suas manifestações espirituais ou físicas" ${ }^{29}$.

Como características fundamentais, nos termos do artigo 20 do Código Civil, com exceção de casos previstos em lei, "os direitos da personalidade são intransmissíveis e irrenunciáveis, não podendo o seu exercício sofrer limitação voluntária”.

\footnotetext{
${ }^{29}$ BELTRÃO, Silvio Romero. Direitos da personalidade. 2. ed. São Paulo: Atlas, 2014, p. 12.
} 
Como exemplos dessa categoria de direitos, Carlos Alberto Bittar aponta os seguintes: vida, integridade física, corpo, partes separadas do corpo, cadáver, imagem, voz, liberdade, intimidade, integridade psíquica, segredo, identidade, honra, respeito e criações intelectuais ${ }^{30}$.

Levando em conta o contexto da Wikipédia, não apenas como uma ferramenta popular de pesquisa geral, mas, sobretudo, a credibilidade social que desfruta, é de se concluir que os direitos como intimidade, imagem e honra são os que têm maior potencial para serem violados por inserções ilícitas em páginas que retratem pessoas.

Tais direitos são objeto de proteção pelo ordenamento jurídico pátrio, a começar pela Constituição Federal de 1988 que, em seu artigo 5º, inciso X, estatui serem "invioláveis a intimidade, a vida privada, a honra e a imagem das pessoas, assegurado o direito a indenização pelo dano material ou moral decorrente de sua violação".

O direito à intimidade, na lição de Carlos Alberto Bittar, se revela como a faculdade de "não exposição a conhecimento de terceiro de elementos particulares da esfera privada do titular" ${ }^{\prime \prime}$, o que abrange um leque amplo de situações, tais como: vida familiar, preferências e gostos, hábitos, afeições, entretenimentos, etc ${ }^{32}$.

Aliás, a teor do artigo 21 do Código Civil: "A vida privada da pessoa natural é inviolável, e o juiz, a requerimento do interessado, adotará as providências necessárias para impedir ou fazer cessar ato contrário a esta norma".

$O$ reconhecimento do direito à honra se justifica pela necessidade da defesa da reputação da pessoa que, em seu aspecto objetivo, "compreende o bom nome e a fama de que desfruta no seio da coletividade, enfim, a estima que a cerca nos seus ambientes familiar, profissional, comercial ou outro"33. Já em seu aspecto subjetivo, o direito à honra abrange "o sentimento pessoal de estima, ou a consciência da própria dignidade" ${ }^{34}$ que o indivíduo cultiva sobre si mesmo.

Por fim, o direito à imagem possui caráter dúplice. Pode referir-se à chamada "imagem-retrato", ou seja, "o direito que a pessoa tem sobre sua forma

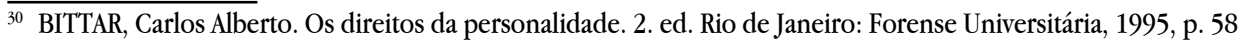
e seg.

${ }^{31}$ Idem, p. 104.

32 Allessandra Helena Neves noticia que alguns autores entendem intimidade e vida privada como a mesma coisa, mas essa posição não seria a mais acertada, pois a intimidade corresponderia à "esfera mais restrita e recolhida da privacidade, ou seja, tudo aquilo que a pessoa teria a prerrogativa de excluir absolutamente do conhecimento alheio, pois só a ela pertence". NEVES, Allesandra Helena. Direito de autor e direito à imagem. Curitiba: Juruá, 2011, p. 165-166.

33 BITTAR, Carlos Alberto, op. cit., p. 125.

${ }^{34}$ Idem, p. 125.
} 
plástica e respectivos contornos" ${ }^{\prime 3}$, mas também pode ligar-se à denominada "imagem-atributo", hipótese em que, na explicação de Luiz Alberto David Araújo, diz respeito ao "conjunto de característicos apresentados socialmente por determinado indivíduo" ${ }^{\prime 3}$.

Nesse campo, Leonardo Zanini apregoa que o "indivíduo tem o direito de se ver representado corretamente, pelas suas reais características, sem alteração de sua história, das suas ideias, da sua conduta, de seu estilo próprio de vida" ${ }^{37}$.

Fato é que os danos resultantes da violação de qualquer direito, seja de personalidade ou não, devem ser indenizados, segundo estabelece o artigo 927 do Código Civil, ou seja, "Aquele que, por ato ilícito (arts. 186 e 187), causar dano a outrem, fica obrigado a repará-lo".

A obrigação de indenizar, como regra geral, pressupõe a presença de culpa (negligência, imperícia ou imprudência) ou dolo por parte do causador do dano. Daí a designação de responsabilidade civil subjetiva. Todavia, essa circunstância pode ser afastada, o que coloca em cena a responsabilidade objetiva que independe da aferição de culpa ${ }^{38}$.

Assim ocorre, por exemplo, em face das pessoas jurídicas de direito público e as de direito privado prestadoras de serviços públicos $\left(\$ 6^{\circ}\right.$ do artigo $37 \mathrm{da}$ Constituição de 1988), bem como nas relações de consumo (artigo 12 do Código de Defesa do Consumidor) ou, ainda, "quando a atividade normalmente desenvolvida pelo autor do dano implicar, por sua natureza, risco para os direitos de outrem" (artigo 20, parágrafo único, do Código Civil).

Evidentemente, sempre será necessária, para que não se diga indispensável, a presença de um nexo causal que, nos dizeres de Nehemias Domingos de Melo, corresponde ao "liame que liga o dano ao causador (responsabilidade subjetiva) ou ao responsável pela atividade (responsabilidade objetiva)"39.

Portanto, certas situações excluem ou amainam a obrigação de indenizar,

35 BITTAR, Carlos Alberto, op. cit., 1995, p. 87.

${ }^{36}$ ARAÚJO, Luiz Alberto David. A proteção constitucional da própria imagem. 2. ed. São Paulo: Verbatim, 2013, p. 28. Porém, é certo que o direito à imagem não chega a se confundir com o direito à honra. Ambos se constituem em bens jurídicos diversos, segundo Silvio Romero Beltrão. BELTRÃO, Silvio Romero, ob. cit., p. 184.

37 ZANINI, Leonardo. Os direitos da personalidade póstumos na perspectiva do direito de autor. 2013. 423f. Tese (Doutorado em Direito Civil) - Faculdade de Direito da Universidade de São Paulo, São Paulo, 2013, p. 108.

${ }^{38}$ Segundo assevera Thereza Cristina Nahas: "Representa a responsabilidade subjetiva a regra geral do sistema de direito privado, constituindo a responsabilidade objetiva exceção". NAHAS, Thereza Cristina. Culpa in elegendo e in vigilando e a responsabilidade do empregador. Revista IOB Trabalhista e Previdenciária, n. 244, out. 2009 , p. 16.

39 MELO, Nehemias Domingos de Melo. Da culpa e do risco como fundamentos da responsabilidade civil. 2. ed. São Paulo: Atlas, 2012, p. 178. 
como são os casos da culpa exclusiva da vítima, o fato exclusivo de terceiro e a culpa concorrente. Afinal, no que concerne à culpa exclusiva, ainda segundo Nehemias Domingos de Melo, se "a vítima é quem provocou o evento danoso, tendo o agente sido tão somente o instrumento pelo qual o mal se materializou, evidentemente não há falar-se em indenização" ${ }^{* 0}$.

Resta agora enfocar como as regras atinentes à responsabilidade civil se aplicam nos casos de inserções danosas na Wikipédia, notadamente para casos de menoscabo a direitos como intimidade, vida privada, imagem e honra das pessoas.

De fácil solução são as inserções de fatos, dados ou informações inverídicas. Nessas hipóteses, em havendo danos, o dever de indenizar é evidente, mesmo que tenha agido o ofensor com mera culpa. A situação, aliás, encaixa-se perfeitamente na previsão do artigo 927 do Código Civil.

O mesmo entendimento é válido para a mera emissão de opiniões ou críticas de cunho pejorativo, visto não ser a Wikipédia, conforme já visto acima, o local adequado para esse tipo de manifestação, não se podendo considerar essa vedação como contrária ao direito constitucional de liberdade de expressão (artigo $5^{\circ}$, incisos IV e IX, da Constituição de 1988).

É que os usuários da enciclopédia, ao ultimarem inserções em seu bojo, voluntariamente restringem a extensão do aludido direito constitucional, de maneira a exercê-lo dentro dos contornos claramente estipulados na Wikipédia. Trata-se de uma submissão consensual, portanto.

Ademais, aceitar que as inserções possam ter caráter meramente opinativo seria o mesmo que aceitar a desfiguração original da Wikipédia, o que não nos parece razoável, pois, conforme já visto, trata-se de uma ferramenta bastante funcional que goza de credibilidade perante o grande público.

Todavia, surge a questão das inserções de cunho verídico, mas que, em face do respectivo conteúdo, acabam por atingir direitos da personalidade da pessoa objeto das observações.

Seria o caso, por exemplo, de edições que retratem condenações judiciais criminais ou mesmo cíveis que exponham falhas no caráter do sujeito ( $v . g$. improbidade administrativa). Mesmo que os fatos sejam verdadeiros, é inegável que a notícia dessas condenações gera dano à reputação do indivíduo (o que engloba direitos como honra e imagem).

Porém, em se tratando de fatos verdadeiros, pensamos não ser razoável 
impedir a divulgação, prevalecendo em tais situações o direito de informar e de se informar, também protegidos constitucionalmente. Entretanto, é de rigor não existir a intenção de fazer transparecer uma falsa percepção da realidade. É que, segundo expõe Anderson Schreiber, "a difusão da verdade pode gerar responsabilidade, dependendo do contexto e o modo como vem presentada" ${ }^{41}$.

Isso poderia ocorrer, por exemplo, no caso de um jornalista especializado em análise econômica que, sistematicamente, defenda a elevação da taxa de juros como remédio contra a inflação e cujo irmão ou parente próximo trabalhe em instituição financeira. A mera inserção na Wikipédia acerca da defesa da alta dos juros não gera dano, ainda mais porque se trata de uma informação verdadeira.

Todavia, se também for acrescentado que o irmão ou parente labora em instituição financeira que, por pressuposto, tem interesse nesse tipo de política econômica, numa alusão, ainda que velada, de que os laços familiares prevalecem sobre a convicção do retratado, haverá provável dano à imagem ou à honra, considerando que jornalistas são respeitados na medida de sua credibilidade e independência.

Evidentemente, tudo depende das circunstâncias presentes em cada caso concreto. De qualquer forma, em qualquer hipótese, sobrevindo danos materiais ou morais, deve ocorrer a competente indenização. Porém, enquanto os danos materiais ( $v . g$. prejuízo econômico decorrente do abalo da reputação) devem ser demonstrados em juízo, o mesmo não é exigido em relação aos danos morais, que se manifestam in re ipsa, isso é, nascem do próprio ilícito.

É o que, por exemplo, referindo-se à jurisprudência da Corte, decidiu a $3^{\mathrm{a}}$ Turma do Superior Tribunal de Justiça em 05 de agosto de 2014, nos autos do Ag. Rg. no REsp. n 510.041 (Rel. Min. Sidnei Beneti). Segundo a ementa do acórdão:

De acordo com a jurisprudência desta Corte, 'o dano moral não depende de prova; acha-se in re ipsa' (REsp 296.634/RN, Rel. Min. BARROS MONTEIRO, DJ 26.8.2002), pois 'não há falar em prova do dano moral, mas, sim, na prova do fato que gerou a dor, o sofrimento, sentimentos íntimos que o ensejam' (REsp 86.271/SP, Rel. Min. CARLOS ALBERTO MENEZES DIREITO, DJU 9.12.97).

\section{RESPONSABILIZAÇÃO DA EMPRESA POR ATOS DE PESSOA A SEU SERVIÇO}

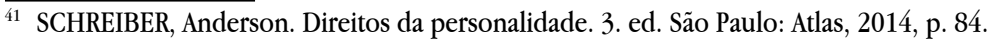




\section{JUNTO À WIKIPÉDIA}

$\mathrm{Na}$ órbita civil, alguém que não tenha praticado um ato danoso somente pode ser chamado a indenizar quando a lei expressamente assim determinar. Nesse contexto, no direito brasileiro, é antiga a regra que estatui ser a empresa (seja sociedade ou firma individual) responsável por atos praticados por seus empregados, agentes ou prepostos.

É que, segundo Enoque Ribeiro dos Santos, já "que o sujeito é privilegiado pelas vantagens ou benefícios do negócio ou atividade, deve responder por possíveis indenizações que essa atividade possa ocasionar" ${ }^{\text {”2 }}$.

O primeiro diploma normativo que expressamente previu a responsabilidade da empresa pelos danos causados por agentes a seu serviço foi o Decreto $\mathrm{n}^{0} 2.681$, de 07 de dezembro de 1912, conhecido como Lei das Estradas de Ferro, cujo artigo 18 determinou o seguinte:

Art. 18 - Serão solidários entre si e com as estradas de ferro os agentes por cuja culpa se der o acidente. Em relação a estes, terão as estradas direito reversivo.

Poucos anos depois, o artigo 1.521, III, do Código Civil de 1916, estipulou serem também responsáveis pela reparação "O patrão, amo ou comitente, por seus empregados, serviçais e prepostos, no exercício do trabalho que lhes competir, ou por ocasião deles (art. 1.522)". Desse modo, a regra antes adstrita às Estradas de Ferro passou a abranger todas as relações civis.

Em 1963, a Súmula 341 do Supremo Tribunal Federal afastou quaisquer dúvidas ainda em voga ao assentar que "É presumida a culpa do patrão ou comitente pelo ato culposo do empregado ou preposto". Nem seria preciso dizer, como, aliás, não foi dito, que o mesmo se aplica a eventuais atos dolosos.

A partir de então passou a ser despiciendo à vítima demonstrar que o patrão escolheu mal ou não vigiou corretamente a pessoa contratada (hipóteses da culpa in eligendo e in vigilando), bastando provar a existência de nexo causal entre a atuação culposa do preposto (seja por ação ou omissão) e os danos.

A mesma orientação foi observada em outras normas ( $v . g$. artigo $268, \S 1^{\circ}$, do Código Brasileiro de Aeronáutica ${ }^{43}$ e artigo 34 do Código de Defesa do Consumidor). Aliás, o artigo 932, III, do Código Civil de 2002, possui redação semelhante àquela de

\footnotetext{
42 SANTOS, Enoque Ribeiro dos. Responsabilidade objetiva e subjetiva do empregador em face do Código Civil. 3. ed. São Paulo: LTR, 2015, p. 24.

${ }^{43}$ Trata-se da Lei $\mathrm{n}^{0} 7.565$, de 19 de dezembro de 1986.
} 
1916, de maneira a estender a responsabilidade ao "empregador ou comitente, por seus empregados, serviçais e prepostos, no exercício do trabalho que lhes competir, ou em razão dele".

Tem-se entendido que "Malgrado a responsabilização objetiva do empregador, esta só exsurgirá se, antes, for demonstrada a culpa do empregado ou preposto, à exceção, por evidência, da relação de consumo". É o que decidiu, em 17 de fevereiro de 2014, no Ag. Rg. no REsp. $n^{0} 1.411 .569$, a $4^{\mathrm{a}}$ Turma do STJ (Rel. Min. Marco Buzzi).

Portanto, para que se cogite da responsabilidade da empresa, é necessário que o sujeito a seu serviço tenha, no mínimo, atuado culposamente, salvo em se tratando de relações de consumo onde a demonstração da culpa é desnecessária (artigo 12 do CDC). Também é desnecessário provar a culpa "quando a atividade normalmente desenvolvida pelo autor do dano implicar, por sua natureza, risco para os direitos de outrem" (parágrafo único do artigo 927 do Código Civil).

Igualmente fica dispensada a prova da presença de culpa quando os danos tiverem origem em prestação de serviço público, seja por pessoa jurídica de direito público ou de direito privado em regime de concessão ou permissão, nos termos do $\S 6^{\circ}$ do artigo 37 da Constituição de 1988.

Porém, em quaisquer das hipóteses acima, a responsabilidade da empresa somente nasce em face de atos ou omissões que possuam alguma ligação, ainda que indireta, com a situação laboral do causador do dano. O exemplo clássico é a obrigatoriedade de reparar os prejuízos causados por veículo conduzido de forma imprudente por funcionário.

Seria rematado absurdo pretender responsabilizar o empregador, por exemplo, pelo fato de um funcionário qualquer, a partir de computador localizado em sua residência, propalar expressões injuriosas ou difamantes em redes sociais, incluindo a Wikipédia. Nesse caso, obviamente, não haveria qualquer liame entre a situação laboral e o dano resultante, salvo se houver prova, por exemplo, de que o ilícito ocorreu a mando do patrão.

Agora, e se essas mesmas ofensas forem lançadas a partir de um computador de propriedade da empresa?

Mesmo que, nesse caso, o ato ilícito não tenha relação com a atividade laboral do sujeito, é fato que o dano teve origem na má utilização de um equipamento pertencente à empresa. Isso é suficiente para fazer surgir o nexo de causalidade 
entre o fato e o dano. Tal nexo causal permanece hígido mesmo que o ato praticado encontre-se fora das funções usuais desempenhadas pelo causador do dano ou, ainda, tenha o evento ocorrido fora do horário de trabalho.

Nesse ponto, Silvio de Salvo Venosa exemplifica que

mesmo em feriado, se um veículo com o logotipo e as cores de uma empresa ocasiona danos, tudo é no sentido de que a atividade do causador do dano está relacionada com o emprego ou situação assemelhada, devendo assumir a responsabilidade a pessoa jurídica decantada e divulgada no veículo causador do dano [...] de nada adianta a pessoa jurídica defender-se para alegar que o motorista estava de folga e se dirigia a um jogo de futebol ${ }^{44}$.

Ainda segundo o autor, aquele "que desempenha uma função eventual para outrem também responsabiliza o terceiro" ${ }^{\text {45 }}$. No mesmo diapasão, enfatiza Maria Helena Diniz que o "serviço pode consistir numa atividade duradoura ou num ato isolado" ${ }^{46}$. Assim, conclui-se não ser de rigor a existência de um vínculo trabalhista ou de hierarquia em face do sujeito que causa o dano para que surja a responsabilidade da empresa indenizar.

Esse foi, aliás, o entendimento adotado pela $4^{\mathrm{a}}$ Turma do STJ, em 12 de abril de 2012, no REsp. no 1072.577 (Rel. Min. Luís Felipe Salomão):

[...] Tanto em casos regidos pelo Código Civil de 1916 quanto nos regidos pelo Código Civil de 2002, responde o empregador pelo ato ilícito do preposto se este, embora não estando efetivamente no exercício do labor que lhe foi confiado ou mesmo fora do horário de trabalho, vale-se das circunstâncias propiciadas pelo trabalho para agir, se de tais circunstâncias resultou facilitação ou auxílio, ainda que de forma incidental, local ou cronológica, à ação do empregado $[\ldots]$.

Também não afasta a responsabilidade da empresa, segundo a lição de Cristiano Chaves de Farias et al., "a circunstância de o dano resultar de ato praticado contra as ordens do empregador" ${ }^{\prime \prime}$. Logo, no caso das inserções indevidas lançadas na Wikipédia, o fato de, eventualmente, haverem sido dadas ordens, mesmo que por escrito, para que os funcionários não acessassem páginas eletrônicas desvinculadas

\footnotetext{
44 VENOSA, Silvio de Salvo. Direito civil. 15. ed. São Paulo: Atlas, 2015, vol. IV, p. 101.

${ }^{45}$ Idem, p. 101.

${ }^{46}$ DINIZ, Maria Helena. Curso de direito civil brasileiro. 28. ed. São Paulo: Saraiva, 2014, vol. 7, p. 598.

${ }^{47}$ FARIAS, Cristiano Chaves de; ROSENVALD, Nelson; NETTO, Felipe Peixoto Braga. Curso de direito civil. Salvador: Jus Podivm, v. 3, 2014, p. 623.
} 
da atividade laboral é irrelevante.

\section{PARÂMETROS PARA A INDENIZAÇÃO PELOS DANOS MORAIS}

Evidentemente, a prática dos ilícitos, objeto do presente texto (violações a direitos de personalidade), gera o dever de indenizar, seja quanto aos danos materiais ou morais, a teor do que dispõem os artigos 186 e 927, ambos do Código Civil de 2002.

A aferição dos danos materiais, via de regra, coaduna-se com parâmetros tradicionais de contabilização de prejuízos. Desse modo, por exemplo, caso uma inverdade lançada na Wikipédia gere a perda de prestígio de um escritor e disso resulte a venda de menos livros, a indenização pelos danos materiais deverá equivaler à perda de receita pelas obras não comercializadas.

É certo que, dependendo do caso concreto, a demonstração do prejuízo material sofrido pode ser bastante complexa, porém, uma vez feita essa prova, naturalmente deverá o juiz acolher o pedido formulado pela vítima.

Porém, no que tange aos danos morais, essa aferição é mais complexa, devendo ser consideradas circunstâncias peculiares de cada caso. Como avaliar o dissabor sofrido pelo escritor do exemplo acima? Simplesmente não há padrões objetivos ou legalmente impostos. Cabe ao juiz, portanto, arbitrar o valor do dano moral em atenção às peculiaridades da lide.

O que se tem entendido, segundo expõe Eduardo C. B. Bittar, é que "a dosimetria deve também mais que reparar, também advertir para a não disseminação de práticas similares” ${ }^{\$ 8}$. Desse modo, o valor do dano moral deve ser arbitrado de modo a exercer uma função dúplice: de um lado, proporcionar o ressarcimento à vítima $\mathrm{e}$, de outro, desestimular ou a repetição do mesmo comportamento futuramente.

Nesse sentido, a "indenização deve ser fixada em termos razoáveis, não se justificando que a reparação venha a constituir-se em enriquecimento sem causa" da vítima. É o que decidiu, em 03 de outubro de 2000, a $4^{a}$ Turma do Superior Tribunal de Justiça, nos autos do REsp. no 267.529 (Rel. Min. Sálvio de Figueiredo Teixeira). No mesmo sentido, em julgamento mais recente, a mesma $4^{\mathrm{a}}$ Turma do STJ, em 17 de novembro de 2015, no bojo do Ag. Rg. no AREsp. no 261.339 (Rel. Min. Marco

\footnotetext{
$\overline{48}$ BITTAR, Eduardo C. B., op. cit., 1995, p. 282.
} 
Buzzi), deixou assentado que:

[...] Não existem critérios fixos para a quantificação do dano moral, devendo o órgão julgador ater-se às peculiaridades de cada caso concreto, de modo que a reparação seja estabelecida em montante que desestimule o ofensor a repetir a falta, sem constituir, de outro lado, enriquecimento sem causa [...].

Obviamente, o montante não pode ser demasiadamente baixo ou mesmo irrisório. Nessa linha, em 01 de setembro de 2015, a já citada $4^{\mathrm{a}}$ Turma do STJ, nos autos do Ag. Rg. no AREsp. n 742.860 (Rel. Min. Marco Buzzi), decidiu que o:

[...] entendimento pacificado no Superior Tribunal de Justiça é de que o valor estabelecido pelas instâncias ordinárias a título de indenização por danos morais pode ser revisto nas hipóteses em que a condenação se revelar irrisória ou exorbitante, distanciando-se dos padrões de razoabilidade [...].

Portanto, necessita o juiz arbitrar uma quantia que proporcione restaurar o bem-estar da pessoa lesada, levando em conta sua situação socioeconômica. Não sendo isso possível em seus exatos termos, conforme decidiu, em 26 de fevereiro de 2013, a $1^{\text {a }}$ Turma do Supremo Tribunal Federal, nos autos dos Embargos de Declaração em Recurso Extraordinário com Agravo no 641.487 (Rel. Min. Luiz Fux), o montante "deve representar para a vítima uma satisfação capaz de amenizar de alguma forma o sofrimento impingido".

Aliás, nesse mesmo julgamento, a finalidade dissuasória desse tipo de indenização restou igualmente transparecida, tendo sido reconhecido como "necessária a majoração do quantum indenizatório fixado na sentença, uma vez que o valor arbitrado - $\mathrm{R} \$ 250,00$ não atende a finalidade punitiva, pedagógica e compensatória".

A necessidade da conjugação da função indenizatória (ou reparatória) com a pedagógica (ou dissuasória) na reparação do dano moral vem sendo reconhecida pela jurisprudência. Vale aqui transcrever trecho de julgamento realizado em $17 \mathrm{de}$ novembro de 2015, igualmente da $4^{\mathrm{a}}$ Turma do STJ, no Ag. Rg. no AREsp. $\mathrm{n}^{\mathrm{0}} 578.903$ (Rel. Min. Marco Buzzi):

[...] 1. Indenização por dano moral majorada de $\mathrm{R} \$ 20.000,00$ (vinte mil reais) para $\mathrm{R} \$ 100.000,00$ (cem mil reais). Flagrante irrisoriedade em razão de peculiaridade constatada no caso concreto. Hipótese em que reconhecido o abalo extrapatrimonial decorrente da recusa de internação de paciente portadora de doença grave, em situação de 
emergência, porque integrante do rol de pacientes não 'rentáveis'. Flagrante má-fé inserta na conduta discriminatória do nosocômio. Necessária garantia da função pedagógico-punitiva da reparação. Enriquecimento sem causa da vítima não configurado. Observância dos princípios da razoabilidade e da proporcionalidade [...].

$O$ trecho acima transcrito deixa clara a necessidade de também serem considerados na fixação do valor do dano moral o grau de culpa ou dolo com que agiu o ofensor, bem como o seu porte econômico.

Evidentemente, na linha do que decidiu a $3^{\text {a }}$ Turma do STJ, em 20 de novembro de 2012, nos autos do REsp. 1.102.756 (Rel. Min. Nancy Andrighi), para "o arbitramento do montante devido, o julgador deve fazer uso de sua experiência e do bom senso, atento à realidade da vida e às peculiaridades da hipótese em discussão".

Em suma, o valor arbitrado a título de dano moral, dentro das circunstâncias do caso concreto, deve ser suficiente para reparar o bem-estar da vítima, possibilitando a obtenção de algum tipo de satisfação em contrapartida ao dissabor sofrido, mas sem implicar em enriquecimento sem causa, o que requer consideração a respeito da sua situação socioeconômica.

Ao mesmo tempo, a quantia deve atender à função dissuasória ou pedagógica, desestimulando o mesmo comportamento pelo agressor, levando-se em conta, para tanto, o grau de culpa e ou dolo apresentados e também o respectivo porte econômico.

Ocorre que não há notícia de que tenha até hoje algum Tribunal brasileiro decidido a respeito da indenização a danos a direitos de personalidade gerados por inserções inverídicas ou de cunho pejorativo em páginas da Wikipédia.

Em relação ao Facebook, por exemplo, já existem alguns precedentes. São casos de ofensas ou criação de "perfis falsos" nessa rede social e que geraram danos à intimidade, à imagem e à honra das pessoas. Nesse campo, por exemplo, a $1^{\mathrm{a}}$ Câmara de Direito Privado do Tribunal de Justiça de São Paulo, em 15 de dezembro de 2015, nos autos da apelação cível no 0041166-92.2012.8.26.0001 (Rel. Des. Francisco Loureiro), fixou os danos morais em $\mathrm{R} \$ 10.000,00$, conforme a ementa abaixo:

AÇÃO DE OBRIGAÇÃO DE FAZER E INDENIZATÓRIA POR DANO MORAL. Ofensas à recorrente, produtora na área de áudiovisual, por meio da rede social Facebook, em grupo fechado de produtores. Problema agravado pelo fato de as ofensas serem veiculadas por 
meio do grupo fechado, inseridas no meio social e profissional da ofendida. Manifestações injuriosas e difamatórias que ultrapassam o direito de crítica e de livre manifestação. Liberdade de expressão que não deve se sobrepor aos direitos fundamentais da honra e da privacidade. Linguagem coloquial e informal usada na Internet que tem limites na honra alheia. Comando ao FACEBOOK de retirar as mensagens ofensivas, devidamente identificadas pela autora. Dever do corréu Roberto de indenizar a autora por danos morais. Critérios de fixação dos danos morais. Funções ressarcitória e punitiva. Danos morais fixados em $\mathrm{R} \$ 10.000,00$. Recurso provido.

No mesmo Tribunal, em caso assemelhado, os danos morais restaram arbitrados em $\mathrm{R} \$ 15.000,00$ pela $8^{\mathrm{a}}$ Câmara de Direito Privado (apelação cível $\mathrm{n}^{\mathrm{o}}$ 0003230-62.2013.8.26.0368, j. 16 de abril de 2015, Rel. Des. Cezar Luiz de Almeida). Em outro caso do mesmo gênero, os danos morais, inicialmente fixados em R\$ $15.000,00$ em $1^{\text {a }}$ Instância, foram reduzidos para $\mathrm{R} \$ 10.000,00$ pela $7^{\mathrm{a}}$ Câmara de Direito Privado (apelação cível $n^{0}$ 1006260-87.2014.8.26.0066, j. 07 de junho de 2015, Rel. Des. Ramon Mateo Júnior).

Contudo, em nosso entendimento, ofensas a direitos como intimidade, honra ou imagem, quando perpetradas no âmbito da Wikipédia, têm potencial mais danoso do que as mesmas violações manifestadas em outras redes sociais, por exemplo, o Facebook. É que, conforme já aventado acima, a Wikipédia conquistou notória credibilidade social, sendo o conteúdo exibido pela enciclopédia geralmente aceito pelo grande público como verdadeiro, ou, no mínimo, como confiável.

Assim, os danos morais oriundos de violações a direitos de personalidade no âmbito da Wikipédia são presumivelmente mais gravosos do que as mesmas ofensas ocorridas em outras redes sociais que não desfrutam do mesmo prestígio. É indispensável, portanto, que essa circunstância especial da Wikipédia seja levada em conta pelos Tribunais no arbitramento das quantias relativas aos danos morais quando chamados a decidir a respeito.

\section{CONCLUSÕES}

Em face do acima exposto, é possível concluir que a Internet, fenômeno típico da chamada Sociedade da Informação, representou um novo paradigma na maneira de os seres humanos se comunicarem.

Porém, não obstante todos os benefícios trazidos pela Internet, é fato que a 
liberdade inerente à sua operação representa um desafio à preservação de direitos da personalidade, principalmente em se tratando das chamadas redes sociais, terrenos férteis para a proliferação de ofensas à intimidade, imagem e honra dos indivíduos.

Considerando que a Wikipédia é uma enciclopédia de cunho colaborativo, inserções inverídicas, opiniões de cunho depreciativo ou ofensas lançadas em relação a pessoas ali retratadas, caso representem violações a direitos de personalidade, devem ser indenizadas, seja no que tange aos danos materiais, seja quanto aos morais.

O mesmo deve ocorrer em face da inserção de fatos verdadeiros, mas alocados dentro de um contexto malicioso ou com potencial para gerar uma interpretação errônea ou distorcida de determinada realidade.

Nesse diapasão, a empresa (seja sociedade ou mesmo firma individual) pode ser chamada a indenizar os danos (materiais e morais) causados por empregado, preposto, agente ou pessoa a seu serviço que promova edições na Wikipédia em desacordo com as regras básicas amplamente explicitadas em seu site.

Ainda que pese essa corresponsabilidade requeira alguma relação, mesmo que indireta, com a situação laboral aplicável ao causador do dano, não se exige a presença de um vínculo trabalhista ou de hierarquia, sendo suficiente, para tanto, a utilização de computador de propriedade da empresa.

A responsabilidade do patrão permanece mesmo diante do fato de as inserções ilícitas nada terem a ver com as tarefas laborais contratadas, nem diante da existência de recomendações ou mesmo ordens expressas para o não acesso a sites de redes sociais ou congêneres.

Diversamente dos danos materiais, a apuração dos danos morais, cuja ocorrência se considera in re ipsa, não se harmoniza com parâmetros tradicionais contábeis de aferição.

Assim, o valor do dano moral deve ser arbitrado pelo juiz de modo a exercer uma função dúplice: de um lado, proporcionar o ressarcimento à vítima, mas sem implicar em enriquecimento sem causa e, de outro, desestimular a repetição do mesmo comportamento no futuro.

Não há notícia até o presente momento de que algum Tribunal brasileiro tenha decidido a respeito da indenização a danos a direitos de personalidade gerados por edições em páginas da Wikipédia, embora já existam precedentes nesse campo, por exemplo, em relação ao Facebook. 
Contudo, levando em conta que a Wikipédia conquistou certa credibilidade perante o grande público, os danos morais oriundos de violações a direitos de personalidade no âmbito da enciclopédia eletrônica são presumivelmente mais gravosos do que as mesmas ofensas geradas em outras redes sociais que não desfrutam do mesmo respeito, o que deve ser observado pelos Tribunais quando vieram a ser chamados a decidir a respeito.

\section{REFERÊNCIAS}

ARAÚJO, Luiz Alberto David. A proteção constitucional da própria imagem. 2. ed. São Paulo: Verbatim, 2013.

BARRETO JÚNIOR, Irineu Francisco. Atualidade do conceito de sociedade da informação para a pesquisa jurídica. In: PAESANI, Liliana Minardi (Coord.). $O$ direito na sociedade da informação. São Paulo: Atlas, 2007, p. 61-77.

BELTRÃO, Silvio Romero. Direitos da personalidade. 2. ed. São Paulo: Atlas, 2014.

BITTAR, Carlos Alberto. Os direitos da personalidade. 2. ed. Rio de Janeiro: Forense Universitária, 1995.

BITTAR, Eduardo C. B. Internet, cyberbullyng e lesão a direitos da personalidade: o alcance atual da teoria da reparação por danos morais. Homenagem a José de Oliveira Ascensão. In: SIMÃO, José Fernando; BELTRÃO, Silvio Romero (Coord.). Direito civil: estudos em homenagem a José de Oliveira Ascensão. São Paulo: Altas, 2015. vol. 1 .

BRASIL. Constituição da República Federativa do Brasil de 1988. Disponível em: $<$ http://www.planalto.gov.br/ccivil_03/Constituicao/Constituicao.htm>. Acesso em: 01 fev. 2016.

BRASIL. Decreto n. 2.681, de 07 de dezembro de 1912. Disponível em: < http://www. planalto.gov.br/ccivil_03/decreto/D2681_1912.htm > . Acesso em: 13 fev. 2016.

BRASIL. Lei n. 3.071, de $1^{\circ}$ de janeiro de 1916 (Código Civil). Disponível em: < http://www.planalto.gov.br/ccivil_03/leis/L3071.htm>. Acesso em: 13 fev. 2016. 
BRASIL. Lei n. 7.565, de 19 de dezembro de 1986 (Código Brasileiro de Aeronáutica). Disponível em: <http://www.planalto.gov.br/ccivil_03/Leis/L7565.htm>. Acesso em: 13 fev. 2016.

BRASIL. Lei n. 8.078, de 11 de setembro de 1990 (Código de Defesa do Consumidor). Disponível em: <http://www.planalto.gov.br/ccivil_03/Leis/L8078.htm>. Acesso em: 11 fev. 2016.

BRASIL. Lei n. 10.406, de 10 de janeiro de 2002 (Código Civil). Disponível em: $<$ http://www.planalto.gov.br/ccivil_03/leis/2002/L10406.htm>. Acesso em: $10 \mathrm{fev}$. 2016.

BRASIL. Superior Tribunal de Justiça. AgRg. no AREsp. n. 261.339. Disponível em: $<$ https://ww2.stj.jus.br/processo/revista/documento/mediado/?componente $=$ ATC\&sequencial $=55036178 \&$ num_registro $=201202480400 \&$ data $=20151124 \&$ tipo $=5 \&$ formato $=$ PDF $>$. Acesso em: 10 fev. 2016.

BRASIL. Superior Tribunal de Justiça. AgRg. no AREsp. n. 578.903. Disponível em: $<$ https://ww2.stj.jus.br/processo/revista/documento/mediado/?componente $=$ ATC\&sequencial $=55041549 \&$ num_registro $=201401930368 \&$ data $=20151124 \&$ tipo $=5 \&$ formato $=$ PDF $>$. Acesso em: 10 fev. 2016.

BRASIL. Superior Tribunal de Justiça. AgRg. no AREsp. n. 742.860. Disponível em: $<$ https://ww2.stj.jus.br/processo/revista/documento/mediado/?componente $=$ ATC\&sequencial $=51611735 \&$ num_registro $=201501688202 \&$ data $=20150924 \&$ tipo $=5 \&$ formato $=$ PDF $>$. Acesso em: 10 fev. 2016.

BRASIL. Superior Tribunal de Justiça. AgRg. no REsp. n. 510.041. Disponível em: $<$ https://ww2.stj.jus.br/processo/revista/documento/mediado/?componente $=$ ATC\&sequencial $=36857862 \&$ num_registro $=201400955421 \&$ data $=20140901 \&$ tipo $=5 \&$ formato $=$ PDF $>$. Acesso em: 11 fev. 2016.

BRASIL. Superior Tribunal de Justiça. AgRg. no REsp. n. 1.411.569. Disponível em: $<$ http://www.stj.jus.br/SCON/jurisprudencia/toc.jsp?processo $=1411569 \& \& b=\mathrm{A}$ COR\&thesaurus $=$ JURIDICO\&p $=$ true $>$. Acesso em: 12 fev. 2016.

BRASIL. Superior Tribunal de Justiça. REsp. n. 267.529. Disponível em: < https:// ww2.stj.jus.br/processo/revista/documento/mediado/?componente=IMGD\&se- 
quencial $=265529 \&$ num_registro $=200000718092 \&$ data $=20001218 \&$ formato $=$ PDF>. Acesso em: 10 fev. 2016.

BRASIL. Superior Tribunal de Justiça. REsp. n. 1.072.577. Disponível em: < http:// www.stj.jus.br/SCON/jurisprudencia/toc.jsp?processo $=1072577 \& \& b=$ ACOR\&thesaurus $=$ JURIDICO\&p=true $>$. Acesso em: 12 fev. 2016.

BRASIL. Superior Tribunal de Justiça. REsp. n. 1.102.756. Disponível em: < https:// ww2.stj.jus.br/processo/revista/documento/mediado/?componente $=$ ATC\&sequencial $=23843230 \&$ num_registro $=200802729394 \&$ data $=20121203 \&$ tipo $=5 \&$ for mato $=$ PDF $>$. Acesso em: 10 fev. 2016.

BRASIL.SupremoTribunalFederal.EmbargosdeDeclaraçãoemRecursoExtraordinário com Agravo n. 641.487. Disponível em: < http://www.stf.jus.br/portal/jurisprudencia /istarJurisprudencia.asp?s1 =\%28ARE\%24\%2ESCLA\%2E +E + 641487\%2ENUME\%2E\%29+OU+\%28ARE\%2EACMS\%2E +ADJ2+641487\%2EACMS\%2E\%29\&base $=$ baseAcordaos\&url = http://tinyurl.com/a7lygr9 > . Acesso em: 10 fev. 2016.

BRASIL. TribunaldeJustiçade São Paulo. Apelaçãocíveln. 0041166-92.2012.8.26.0001. Disponível em: $<$ https://esaj.tjsp.jus.br/cjsg/getArquivo.do?cdAcordao $=9080327 \&-$ cdForo $=0 \& v l$ Captcha $=$ exiyk $>$. Acesso em: 12 fev. 2015.

BRASIL. TribunaldeJustiçade São Paulo. Apelaçãocíveln. 0003230-62.2013.8.26.0368. Disponível em: $<$ https://esaj.tjsp.jus.br/cjsg/getArquivo.do?cdAcordao=9144893\&cdForo $=0>$. Acesso em: 12 fev. 2016.

BRASIL. TribunaldeJustiçade São Paulo. Apelaçãocíveln. 1006260-87.2014.8.26.0066. Disponível em: $<$ https://esaj.tjsp.jus.br/cjsg/getArquivo.do?cdAcordao $=8522018 \&$ cdForo $=0>$. Acesso em: 12 fev. 2016.

BRASIL. Tribunal de Justiça do Rio Grande do Sul. Primeira Turma Recursal Cível. Apelação n. 71004356218. Disponível em: < http://www.tjrs.jus.br/busca/search?$\mathrm{q}=$ wi kipedia\&proxystylesheet $=$ tjrs_index\&client $=$ tjrs_index\&filter $=0$ \&getfields $=* \& a b a=$ juris $\&$ entsp $=a_{-} \_$politicasite $\& w c=200 \& w c \_m c=1 \& o e=U T$ F8\&ie $=$ UTF8 \&ud $=1 \& \mathrm{lr}=$ lang_pt\&sort $=$ date $\% 3 \mathrm{AD} \% 3 \mathrm{AS} \% 3 \mathrm{Ad} 1 \& a \mathrm{~s} \_\mathrm{q} j=\&$ as $\mathrm{q}=\&$ requiredfields $=\&$ site $=$ ementario\&as_epq $=\& a s \_o q=\& a s \_e q=\#$ main res_juris $>$. Acesso em: 10 fev. 2016. 
CASTELLS, Manuel. A galáxia da internet. Tradução de Maria Luiza X. de A. Borges. Rio de Janeiro: Zahar, 2003.

DINIZ, Maria Helena. Curso de direito civil brasileiro. 28. ed. São Paulo: Saraiva, 2014. vol. 7 .

FARIAS, Cristiano Chaves de; ROSENVALD, Nelson; BRAGA NETTO, Felipe Peixoto. Curso de direito civil. Jus Podivm, Salvador, v. 3, 2014.

FORGIONI. Paula A. Fundamentos do antitruste. 8. ed. São Paulo: Revista dos Tribunais, 2015.

MELO, Nehemias Domingos de. Da culpa e do risco como fundamentos da responsabilidade civil. 2. ed. São Paulo: Atlas, 2012.

NAHAS, Thereza Cristina. Culpa in elegendo e in vigilando e a responsabilidade do empregador. Revista IOB Trabalhista e Previdenciária, n. 244, p. 14-22, out. 2009.

NEVES, Allesandra Helena. Direito de autor e direito à imagem. Curitiba: Juruá, 2011.

RODRIGUES, Lucas de Oliveira. Cyberbullying. Brasil Escola. Disponível em: $<$ http://brasilescola.uol.com.br/sociologia/cyberbullying.htm > . Acesso em: $06 \mathrm{fev}$. 2016.

SANTOS, Enoque Ribeiro dos. Responsabilidade objetiva e subjetiva do empregador em face do Código Civil. 3. ed. São Paulo: LTR, 2015.

SCHREIBER, Anderson. Direitos da personalidade. 3. ed. São Paulo: Atlas, 2014.

SIQUEIRA JÚNIOR, Paulo Hamilton. Habeas data: remédio jurídico da sociedade da informação. In: PAESANI, Liliana Minardi (Coord.). 0 direito na sociedade da informação. São Paulo: Atlas, 2007, p. 251-274.

TOFFLER, Alvin. A terceira onda. 18. ed. São Paulo: Record, 1980.

VENOSA, Sílvio de Salvo. Direito civil. 15. ed. São Paulo: Atlas, v. IV, 2015.

WIKIPÉDIA. Disponível em: <https://pt.wikipedia.org/wiki/ Wikip\%C3\%A9dia:P\%C3\%A1 gina_principal > . Acesso em: 10 mar. 2016. 
ZANINI, Leonardo Estevam de Assis. Os direitos da personalidade póstumos na perspectiva do direito de autor. 2013. 423f. Tese (Doutorado em Direito Civil) Faculdade de Direito da Universidade de São Paulo, São Paulo, 2013.

Recebido em: 04 de março de 2016 Aceito em: 09 de maio de 2016 